\title{
A CASE OF CONGENITAL ANIRIDIA AND FAMILIAL PHEOCHROMOCYTOMA - WITH SPECIAL REFERENCE TO ANIRIDIA-WILMS' TUMOR SYNDROME
}

\author{
Fumitoshi Ohno, Toshinao Yamano, and Koichi Kataoka \\ Second Department of Internal Medicine, Kochi Medical \\ School, Nankoku City 781-51, Japan
}

\begin{abstract}
Summary A case of bilateral aniridia associated with familial pheochromocytoma in a female of 17 years of age was described. The pheochromocytoma of the patient with aniridia showed a malignant nature, but the pheochromocytoma of her sibling who had no aniridia was benign. This rare association had not been reported and it was discussed in relation to aniridia-Wilms' tumor syndrome.
\end{abstract}

\section{INTRODUCTION}

The association of aniridia and congenital mesenchymal defects, including Wilms' tumor has come to be well known recently, and is called aniridia-Wilms' tumor syndrome (Francois et al., 1977). In addition, association with neoplasmas other than Wilms' tumor, such as gonadoblastoma, haemoangioma and neurofibroma have been reported with the discovery of an increasing number of patients having aniridia and an array of associated findings (Fraumeni and Glass, 1968; Haicken and Miller, 1971; Andersen et al., 1978; Blethen and Taysi, 1981).

Otherwise, chromosomal aberation in cases of aniridia-Wilms' tumor syndrome have been detected recently (Ladda et al., 1974; Andersen et al., 1978). Thus, this syndrome has attracted interest from the teratogenic and onchogenic points of view.

We have recently experienced a case of congenital aniridia associated with familial pheochromocytoma. The case is reported because of the rarity of this combination.

\section{REPORT OF A CASE}

Og., Ya. 17-year-old female

Family history. There was no history of parental consanguinity (Fig. 1). The patient's father had died at 23 years of age of hypertention. The mother is alive 


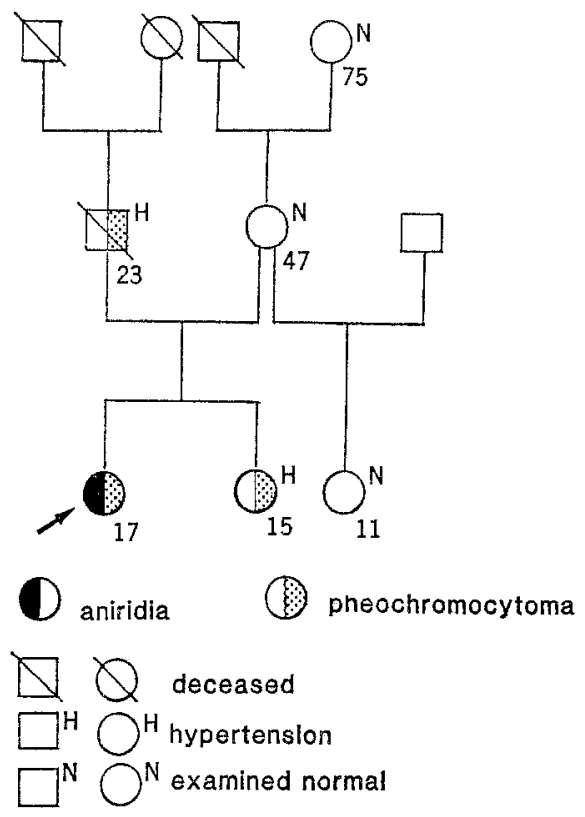

Fig. 1. Family tree of the patient (Og., Y.).

and well. The 15-year-old sister of the patient had marked hypertention, and benign pheochromocytoma had been confirmed by operation at Komatsushima Red Cross Hospital. There was no history of aniridia or other congenital defects or other tumors in this family.

Past history. Photophobia and bilateral aniridia were noted for the first time at 6 months of age. At 15 years of age, pain at the left hypochondrium appeared intermittently and she was treated with antispasmodics. At 17 years of age, she visited Tokushima University Hospital complaining of abdominal pain, and a left upper quadrant mass of the abdomen was noticed for the first time. She was admitted in Mar. 1978 for further examination.

Physical examination. Stature and secondary sex characteristics were normal. No mental abnormality. Bilateral total absence of the iris was noted (Fig. 2). Vision right 0.08 , left 0.06 . Ocular movement was normal and nystagmus was not present. Struma free. B.P. 120/70, lung and heart not remarkable. A $7 \times 7$ $\mathrm{cm}$ hard immobile round mass was palpable in the left upper quadrant of the abdomen. There was pain on palpation and vascular murmur was heard by auscultation. The body was symmetrical without hemihypertrophy. Vascular or pigmented nevis and other anomalies were not noted. The external genitalia were normal. No motor disturbances.

Laboratory data. Urinalysis. protein(-), sugar(-). haematology. $\mathrm{Hb} 13.1$ $\mathrm{g} / \mathrm{dl}$, RBC $470 \times 10^{4}$, WBC 5,900. Analysis of chromosome prepared from periph- 


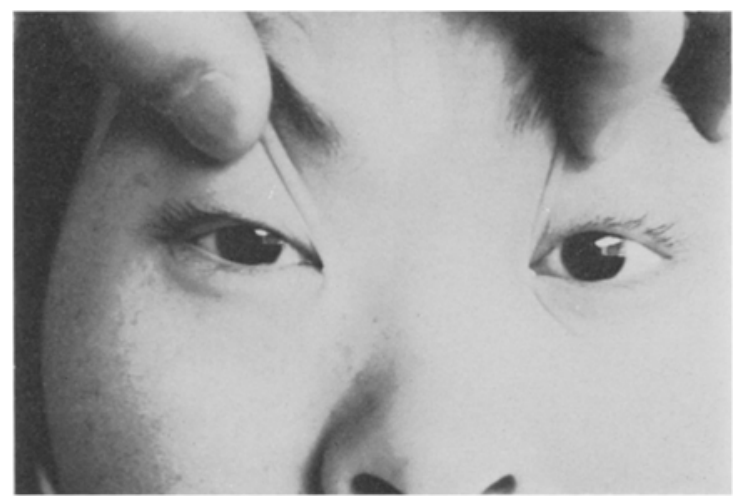

Fig. 2. Bilateral aniridia of the patient. The pupil is large and occupies entire area of the cornea.

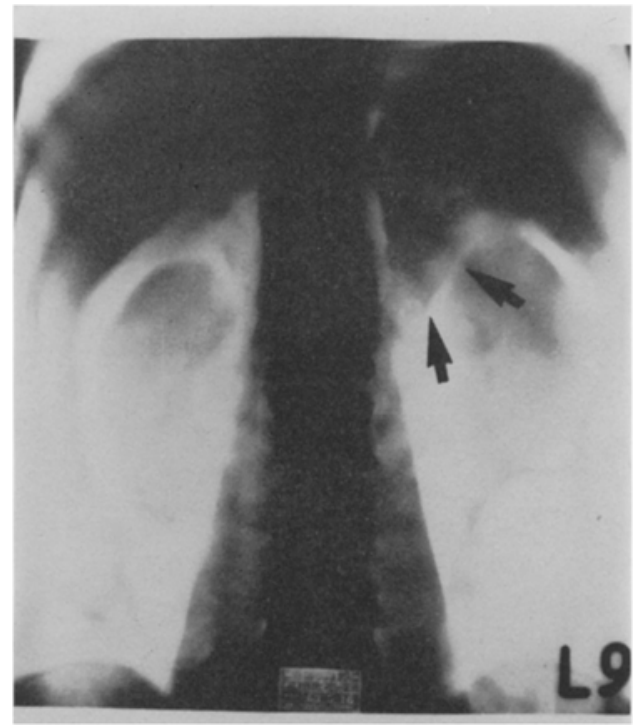

Fig. 3. Retroperitoneal-pneumorenogram of the patient. Arrow indicates left adrenal mass.

eral leucocytes disclosed a normal female karyotype (46XX), and there was no detectable chromosome deletion. Blood chemistry. GOT 10IU, GPT 12IU, LDH $370 \mathrm{IU}$, Bilirubin $0.8 \mathrm{mg} / \mathrm{dl}$, BUN $15.5 \mathrm{mg} / \mathrm{dl}$. Endocrine examinations. Serum thyroxine $11.7 \mu \mathrm{g} / \mathrm{dl}$, calcitonin $0.02 \mathrm{ng} / \mathrm{dl}$. Thyroid scintigram normal, $50 \mathrm{~g}$ GTT normal. Urinary $17-\mathrm{OHCS} 5.9 \mathrm{mg} /$ day, $17-\mathrm{KS} 6.8 \mathrm{mg} /$ day, Urinary homovanilic acid $3.8 \mathrm{mg} /$ day, dopamin $450 \mu \mathrm{g} /$ day, adrenalin $3.3 \mu \mathrm{g} /$ day, $n$-adrenalin $58.3 \mu \mathrm{g} /$ day, metanephrine $0.05 \mathrm{mg} /$ day, $n$-metanephrin $0.11 \mathrm{mg} /$ day, VMA $6.5 \mathrm{mg} /$ day.

Upper gastrointestinal series showed upper displacement of the body of the 
stomach. Excretory urogram showed normal appearance. ${ }^{131}$ I-adrenal scintigram showed left adrenal absence, and retroperitoneal pneumorenogram revealed a left adrenal mass (Fig. 3). From these findings, a left adrenal tumor was strongly suspected.

Hospital course. From physical, laboratoric and roentogenologic studies of this patient and especially from the history of pheochromocytoma in her sibling, silent left pheochromocytoma was most strongly suspected in this case. She recieved laparotomy in May 1978. On the left side of the retroperitoneal area, there was a yellow-white tumor which had the size of an infant's head and grew from the left adrenal. Marked local invasion to the stomach and pancreas was noticed and few regional metastatic lymph nodes were noted. Total extirpation without probe excision was very difficult due to easy bleeding, and it was suspended with the exploratory operation. The microscopic appearance of the specimen was consistent with malignant pheochromocytoma (Fig. 4).

She received no irradiation and was discharged in Oct. 1978, and there followed palliative treatment. She died in Dec. 1980.

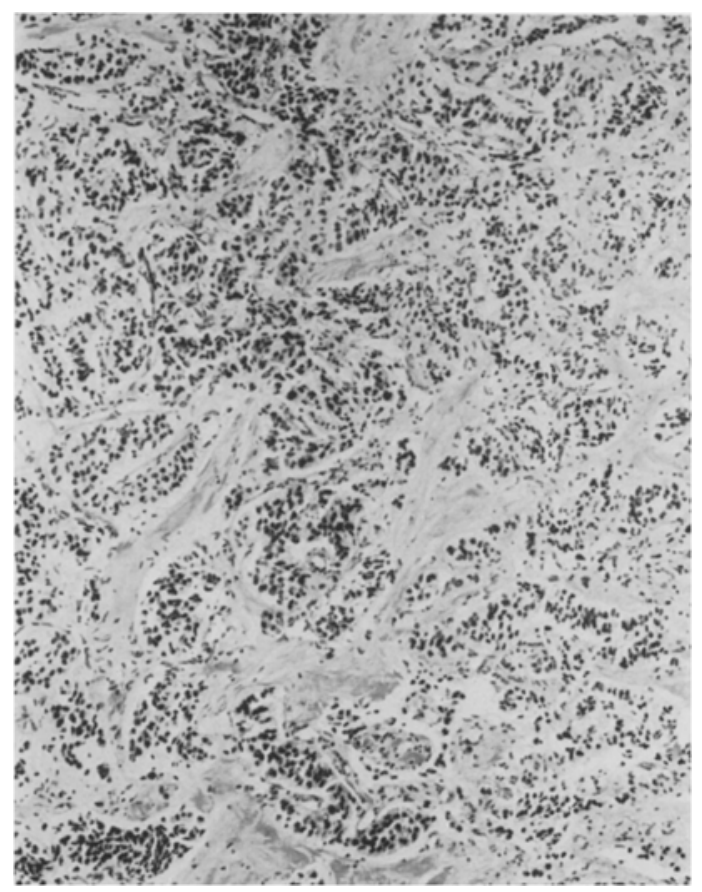

Fig. 4. Histological picture of the left adrenal tumor, showing plemorphic cells separated by thin bands of connective tissue. Irregular hyperchromatic degenerating cells were seen $(\mathrm{HE} \times 70)$. 


\section{DISCUSSION}

Aniridia or congenital absence of the iris, is a hereditary disease. Most affected individuals have nystagmus, cataract and secondary glaucoma resulting in decreased visual acuity. Shaw et al. (1960) showed that two thirds of the cases are due to an autosomal dominant gene with high penetrance. About one third of the cases are sporadic, and are thought to be the result of a new mutation. And this "Sporadic" form of aniridia is associated with an increased incidence of Wilms" tumor. The association was mentioned for the first time in 1953 by Brusa and later by Miller et al. (1964). The association of Wilms' tumor in five of 15 cases of sporadic aniridia was reported by Fraumeni and Glass (1968).

Ladda et al. (1974) recently, reported the partial deletion of chromosome 8 in this syndrome. The association of sporadic aniridia-Wilms' tumor and deletion in the short arm of chromosome 8 has important implications for the genetic causes of childhood cancer and the two-mutation model of tumorigenesis (Kundson and Strong, 1972).

In this article we report what we belive a hitherto undescribed association of aniridia with pheochromocytoma, that may represent another example of this syndrome.

It should be noted, however, that Wilms' tumor and pheochromocytoma are both thought to be neoplastic congenital malformations and that both are often observed to occur familially. Miller et al. (1964) had already pointed out the clinical resemblance between neuroblastoma and Wilms' tumor, and that neuroblastoma might be excessively associated with congenital malformation as Wilms' tumor was. Thereafter, Fraumeni and Glass (1968) reported a case with aniridia and neurofibroma. As neurofibroma and pheochromocytoma have the same neuroectodermal origin aniridia-pheochromocytoma association can be easily expected.

Another characteristic of our case is that pheochromocytoma shows familial occurrence (Malicow, 1977). The father who died young with hypertention was strongly suspected of pheochromocytoma and the patient's sister's pheochromocytoma was confirmed by operation. In addition, it is interesting that pheochromocytoma in the patient with aniridia was malignant both clinically and histologically but the pheochromocytoma in the case of the sibling who had no aniridia seemed to be benign. It may give some proof of the oncogenicity of the aniridia syndrome.

The outline of this paper was read at the 39 th Annual Meeting of the Japanese Society of Internal Medicine, Chu-Shikoku District, 1978.

\section{REFERENCES}

Andersen, S.R., Geertinger, P., Larsen, H.W., Mikkelsen, M., and Warburg, M. 1978. Aniridia, cataract and gonadoblastoma in a mentally retarded girl with deletion of chromosome 11 . Ophthalmologica 176: 171-177. 
Blethen, S.L. and Taysi, K. 1981. Autosomal dominant aniridia in association with craniopharyngioma. Am. J. Dis. Child 135: 575-576.

Francois, J., Coucke, D., and Coppieters, R. 1977. Aniridia-Wilms' tumor syndrome. Ophthalmologica 174: 35-39.

Fraumeni, J.F. and Glass, A.G. 1968. Wilms' tumor and congenital aniridia. J.A.M.A. 206: 823828.

Haicken, B.N. and Miller, D.R. 1971. Simultaneous occurrence of congenital aniridia, hamartoma and Wilms' tumor. J. Pediatr. 78: 497-502.

Kundson, A.G. and Strong, L.C. 1972. Mutation and cancer, neuroblastoma and pheochromocytona. Am. J. Hum. Genet. 24: 514-532.

Ladda, R., Atkins, L., Littlefield, J., Neurath, P., and Marimuihu, K.M. 1974. Computer-associated analysis of chromosomal abnormalities, detection of deletion in aniridia-Wilms' tumor syndrome. Science 185: 784-787.

Malicow, M.M. 1977. One hundred cases of pheochromocytoma at the Columbia presbyterian medical center, 1926-1976. Cancer 40: 1987-2004.

Miller, R.W., Fraumeni, J.F., and Manning, M.D. 1964. Association of Wilms' tumor with aniridia, hemihypertrophy and other congenital malformations. N. Engl. J. Med. 270: 922-927.

Shaw, M.W., Falls, H.F., and Neel, J.V. 1960. Congenital aniridia. Am. J. Hum. Genet. 12: 389415. 